\title{
Patriarcado e loucura no romance brasileiro
}

\section{Resumo:}

O estudo comparativo dos romances Fogo morto, de José Lins do Rego (1943); A menina morta, de Cornélio Penna (1954) e Crônica da casa assassinada, de Lúcio Cardoso (1959) permite entrever o complexo quadro de relações entre forma romanesca e sociedade brasileira. São romances cujos enredos transcorrem no interior ou à sombra do espaço doméstico cujo significado aponta para as especificidades da sociedade brasileira ancorada na estrutura e no funcionamento do modo de produção escravista, expresso pela significativa presença do lar como casa-grande. Assim, os romances captam, pelo viés da prosa introspectiva, a relação entre a esfera da família e a formação do sujeito, aproximando o patriarcado dos traços da loucura.

Palavras-chave: casa-grande, patriarcado, família, romance, introspecção

\section{Abstract:}

\section{Patriarchy and Madness in the Brazilian Novel}

A comparative study of the novels Fogo Morto, by José Lins do Rego (1943); A menina morta, by Cornélio Penna (1954) and Crônica da casa assassinada, by Lúcio Cardoso (1959) allows a glimpse into a complex framework of relations between novelistic form and Brazilian society. They are novels whose plots take place in the interior or in the shadow of the domestic space whose meaning points to the specificities of Brazilian society anchored in the structure and functioning of the slave production mode, expressed by the significant presence of the home as casa-grande. Thus, through the bias of introspective prose, the novels capture 
the relation between the sphere of the family and the formation of the subject, approaching patriarchy to the traces of madness.

Keywords: Big House, patriarchy, family, romance, introspection

Na experiência do romance brasileiro a partir dos anos de 1930 é notável a presença de romances cujos enredos se desenvolvem rente à esfera do mundo privado em detrimento da esfera externa da vida em comum, de modo que o espaço da casa se sobrepõe ao espaço da rua, na contramão da forte presença da cidade no romance moderno ocidental. Pode-se refletir sobre o fenômeno a partir da amplitude que a prosa de tendência introspectiva - afim à ordem da casa - assume no período, para além da ultrapassada dicotomia entre regionalistas e intimistas. Com alterações de rumo e projeto, a potencialidade semântica e sociológica do espaço doméstico continua e se reforça nas décadas seguintes como ocorre com Fogo morto, de José Lins do Rego (1943), A menina morta, de Cornélio Penna (1954) e Crônica da casa assassinada, de Lúcio Cardoso (1959) - objetos desta análise. Nestes casos, trata-se de enredos que transcorrem no interior ou em torno das casas cuja característica mais forte, que nos leva às relações entre literatura e sociedade, é que estas são ou foram casas-grandes, impondo a presença da estrutura de poder do patriarcado rural como aspecto que se entrelaça ao espaço romanesco. De modo que a recorrência ao espaço da casa, a análise e interpretação de suas consequências, permite entrever o complexo quadro de relações entre forma romanesca e sociedade brasileira na experiência posterior aos anos de 1930 - mais especificamente entre as décadas de 40 até meados dos anos 60 - com ênfase nos três romances acima elencados.

Portanto, a aproximação entre as obras é referendada, em primeiro lugar, pelo espaço físico. Este acolhe uma série de características, desvendando-se um recurso privilegiado da memória do Brasil arcaico. Nota-se a presença dos enredos transcorridos no interior ou à sombra das casas ruinosas que, guardiãs da memória e testemunhas da decadência, impõem-se como lócus de interdição à liberdade e ao processo de individuação. Nessas casas, por vezes antropomorfizadas, 
encena-se, pelo viés da prosa de introversão, os modos da sociabilidade brasileira ancorada na vivência doméstica, dada a quase inexistência do espaço externo.

Em segundo lugar, observe-se o modo como, por meio da análise associada aos sentidos contextuais, a casa desvela-se falso refúgio, falsa proteção e assume a roupagem de prisão, de hospício e, finalmente, de espaço tumular. Nesse ponto, note-se a presença que, desde os títulos, é dada à morte: o engenho e a criança estão mortos e a casa, por sua vez, foi assassinada. Qual seria o sentido mais fundo dessa morte à qual os romances se referem?

Sabe-se que a casa é uma imagem que, quase arquétipo, acolhe sentidos que se referem ao retorno à mãe, ao aconchego, à plenitude. A idealidade da morada pode estar contida nas imagens do casulo, do ninho ou da gruta, alusões a um estado de bem-estar primeiro e totalizante o qual, contudo, a experiência do homem no mundo não parece acatar (Bachelard, 1990: 75-99). No caso brasileiro, os romances desvelam a casa como lócus do patriarcado, em nuances variegadas do exercício do poder. Não há como se furtar ao fato de que o predomínio da história como arbítrio, poder e opressão infiltra-se e amalgama-se na constituição ficcional do espaço físico, evidenciando a condição incontornável de como este se faz extensão do social. A suposta natureza primeira do lar inviolável não pode se eximir da totalidade das relações sociais; assim, a casa, literariamente delineada, configura-se, nas palavras de Pierre Bourdieu, "estrutura social em estado objetivado" (Bourdieu, 2013: 136).

Assim, a especificidade da empresa rural brasileira faz do espaço físico da casa-grande célula do poder, base do latifúndio escravocrata, cuja onipresença corta a experiência nacional. Mais do que um espaço social vago e amplo, a casa literariamente formulada comunica-se com a base, a estrutura, em cujo bojo se desenvolve toda a complexa rede que, ancorada na família patriarcal, a ampara e propaga.

Importa acompanhar os matizes que a circunscrição da casa assume ao incidir sobre as subjetividades em jogo; de que modo as relações de dominação infiltram-se nas relações interpessoais moldando a voz e o lugar, o discurso e o corpo - a emancipação ou a sujeição do 
indivíduo. Como a elaboração estética capta a dinâmica da grande propriedade em transição para o mundo livre.

Desse modo, é sob a égide dos casarões, índice da casa-grande enquanto estrutura de poder, que os três romances se desenrolam: assim a sede do engenho Santa Fé em Fogo morto, o Grotão, em A menina morta e a chácara dos Meneses, na Crônica da casa assassinada. Nesse percurso, uma das acepções que a casa emula é a de espaço de confinamento, assemelhando-se a uma prisão.

A segunda parte de Fogo morto se desenvolve sob a grande propriedade. A família antes rica, agora empobrecida, vive encarcerada. Tal acepção emerge no episódio em que Seu Lula se torna obcecado com uma suposta relação entre a filha Neném e um promotor, genro desqualificado aos olhos da fidalguia. Leia-se a passagem:

Começara a chover forte. As portas da casa-grande estavam fechadas. Saiu para examinar os ferrolhos, as trancas. Tudo estava muito bem fechado, Neném não viera para a mesa do chá. Quis que ela viesse. Mandou que a mulher fosse chamá-la. E quando a viu de olhos vermelhos de chorar, com a cabeça baixa, imaginou o ódio que não lhe teria. Era pai, e pai era somente para aguentar as fraquezas dos filhos. Estava sereno. Deus lhe dera calma, força para vencer os tumultos de sua alma. Não falou. Amélia parecia com medo de qualquer coisa. O vento batia nas portas, bulindo com os ferrolhos. Tudo estava muito bem trancado. Então, Seu Lula pôde olhar para a sua filha como uma propriedade sua, que ninguém tocaria (Lins do Rego, 1971: 188)

O senhor decaído fantasia o rapto de sua filha, supõe ser vítima de um complô e a ameaça da desonra aflora violentamente. Quando, na ordem do narrado, a sucessão dos eventos desvenda o erro, escancara-se a paranoia e o distúrbio. A imaginação da grandiosa ofensa - inimigos confabulam contra a nobreza do senhor que, heroicamente, faz justiça com as próprias mãos - seguida do choque diante da realidade mesquinha culmina em um ataque e o senhor cai, fulminado. Em tudo, a cena é a caricatura do mundo do poder senhorial, apequenado e doente, mas sem abrir mão da superioridade de classe que engrossa o caminho para a insanidade. 
O episódio desvenda a casa-grande como cárcere. A sinhazinha guardada a ferrolhos, o senhor de engenho de armas engatilhadas, a proteção que se confunde com a pena, o pai que se faz algoz.

A prisão privada assenta sobre uma ambiguidade de fundo. Por um lado, trata-se da preservação do grupo contra a ameaça de dissolução, expressa pela emergência do mundo do trabalho livre. Daí que à ameaça sucede a defesa, legitimada em termos que radicam na ideologia da família, num caminho de legitimação de modos de violência. Por outro, a suposta proteção é grave violação à individualidade e aos incipientes direitos do cidadão sob o mundo burguês.

Prisão também se torna a fazenda, palco de $A$ menina morta. A vida reduz-se à casa que, por vezes, parece figurar uma cidade:

O corredor largo e escuro que conduzia à cozinha era como uma rua dentro da grande fazenda. Tudo passava por ali e a qualquer hora do dia podiam ser nele encontrados os habitantes do Grotão. Nos armários que ocupavam as paredes, nos lanços entre as poucas janelas gradeadas e abertas para o pátio interno eram guardados os artigos finos vindos do Rio de Janeiro e vindos de países exóticos e longínquos. Suas prateleiras conservavam por todo o ano o perfume forte e apimentado das gulodices, mandadas vir para as festas de Natal e fim de ano, e muitas vezes ali permaneciam durante meses, servidas em sobremesa para as visitas. Durante algumas gerações eles tinham sido os cofres de tesouros que só eram alcançados pelas crianças depois de muitas súplicas e de promessas de bom comportamento, e quase nunca era permitido às pequenas cabeças de cabelos encaracolados se alçarem até o nível das grandes caixas de madeira com gravuras de cores cintilantes, das latas cobertas de desenhos orientais ou figuras inglesas, ou ainda dos longos pacotes azuis rotulados de branco e cheios de letras estrangeiras (Penna, 2001: 80)

Os corredores são ruas em que se encontram os moradores como se estivessem no espaço aberto. Após o narrador comparar os corredores às ruas e o trânsito doméstico à via pública, segue a descrição minuciosa dos víveres. O espaço externo é interno à casa, a amplidão inexistente do mundo se entronca, de súbito, ao relato dos objetos que se chocam com a sugestão da rua. A descrição da variedade da despensa 
faz pensar em uma mercearia de luxo ao expor suas mercadorias. Mas nada ali está à disposição do homem livre, do trabalho ou da troca. Os pertences furtados ou interditos surgem como bens inalcançáveis e signatários do poder.

Em um contexto em que a desigualdade é legitimada pela instituição da escravidão, o único espaço de vida permitido é o da família; daí a casa, corredores e aposentos simularem a convivência civilizada, desmentida constantemente pela base do trabalho compulsório. Em face da escravidão, não há existência mínima da ideia de espaço público, uma vez que este só se organizaria enquanto arena em que se situam iguais (Arendt, 2013: 26-45). À interdição do desabrochar da liberdade se acresce, no contexto nacional, a distinção da reserva; a esse título, conta Gilberto Freyre que os senhores consideravam indignidade sair às ruas, enquanto que a reclusão era índice de fidalguia (Freyre, 2004: 145).

O confinamento ao espaço privado dá conta da recusa ao aflorar da subjetividade pré-moderna, testemunhado pelo medo da liberdade individual diante da eminente abolição. Nesse percurso, observe-se como a prosa capta a reação da sinhá-moça diante da revelação de que a intimidade de suas correspondências fora violada:

(...) descobria-se presa, limitada, prisioneira de alguma coisa difusa e rastejante, que a cercava de forma invisível e a tolhia sem algemas sensíveis, semelhante a ameaças de cegueira ou de surdez, companheiras dos velhos (Penna, 2001: 336).

O domínio do privado é o espaço da família, avesso ao mundo das relações interpessoais livres, do âmbito público, portanto adverso à conquista da cidadania. Do alvorecer do trabalho livre ( $A$ menina morta), passando pela decadência do patriciado rural (Fogo morto), até às angustiantes reminiscências do poder da família mineira $(\mathrm{Crô}-$ nica da casa assassinada) irrompe o esmagamento da subjetividade livre e emancipada, a consciência do fracasso e da culpa, a impossível autolibertação.

Diferentemente de $A$ menina morta, cuja ação se passa no final do século XIX, o palco da enunciação na Crônica da casa assassinada 
é a modernidade. Trata-se da decadência que perdura, da queda como processo constante e inacabado em que o arcaico jaz conservado e reanimado por um processo de modernização de cunho conservador. Uma das muitas imagens da casa na obra pode servir de exemplo:

A casa é a mesma, mas a ação do tempo é bem mais visível: há outras janelas que não se abrem mais, a pintura passou do verde ao tom escuro, as paredes gretaram-se pelo esforço da chuva e, no jardim, o mato misturou-se às flores. Não há como negar, Nina, houve aqui uma transformação desde que você partiu - como que um motor artificial, movido unicamente pelo seu ímpeto, cessou de bater - e a calma que se apossou da casa trouxe também esse primeiro assomo de morte que tantas vezes reponta no âmago do próprio repouso; cessamos bruscamente no tempo, e o nosso lento progresso para a extinção e um clima a que você talvez não se adapte mais. Apesar de tudo, resta louvar o espírito da família Meneses, esse velho espírito que é nosso único ânimo e sustentáculo: este ainda é o mesmo, integral como um alicerce de ferro erguido entre a alvenaria que cede. Você nos encontrará imutáveis em nossos postos, e a Chácara instalada, a esse respeito, na sua latitude habitual. À medida que o tempo passa, se perdemos o respeito e a noção de carência de muita coisa, outras porém se avivam e fortalecem em nosso íntimo: somos assim, por circunstância e por fatalidade, mais Meneses do que nunca - e você o compreenderá desde o primeiro momento em que pisar na Chácara (Cardoso, 128)

Valdo, o narrador aqui, noticia a suspensão do dinamismo inerente à propriedade, responsável pelo desencadear da desagregação. $\mathrm{O}$ repouso é a ruptura com o tempo captado pelo oxímoro "progresso para a extinção". A preparação para a morte, contudo, resiste graças ao "espírito da família Meneses" que permanece, qual "alicerce de ferro". A chácara confunde-se com os valores da tradição da família mineira. É apresentada desde o início como espaço em vias de se dissolver, esboroar. Contudo, o animismo que lhe empresta vida a faz detentora da vontade humana e má de matar. A casa assassinada também assassina, torna-se, a um só tempo, objeto e sujeito, é alvo e algoz, vítima e criminosa. 
Em muitos momentos da narrativa o espaço capta o páthos da experiência da subjetividade arruinada. A personagem central Nina, mulher cuja modernidade e encanto põem a perder o siso da família Meneses, constitui-se a antítese da ordem da casa. Ela encarna a interdita esfera do desejo e da liberdade humanas, acrescidas da beleza esfíngica e da volubilidade dos que não se deixam aprisionar. Sua fragilidade será paradoxalmente sua força: sob a sua presença acelera-se a derrocada da casa-família-tradição. Desejada e proscrita, Nina encarna tudo o que a família anseia e teme.

O dinamismo do processo histórico imprime-se na casa e comunica-se com o corpo de Nina - o qual açambarca a juventude e a doença iminente. A casa emulará um corpo em decomposição, colando-se à imagem da protagonista cujas carnes apodrecem em vida, intercambiando história e natureza. Desse modo, os opostos perfazem um só organismo que une vida e morte: o velho e o novo, a tradição e a ruptura - a casa e Nina.

O caráter paradoxal do apego ao passado em face da emergência do novo, conduzirá a mais uma similitude entre as obras: o desencadeamento dos desequilíbrios psíquicos - a loucura e outros distúrbios. Não só a galeria de personagens ganhará os contornos da loucura, como a casa irá aproximar-se do espaço de confinamento que, para além da prisão, figura um manicômio. A exigência aguda de controle, sob o imperativo da família, desemboca no seu oposto e a subjetividade fracassada encontra-se com a insanidade. Paira sobre esse mundo comandado pelas casas-grandes a aniquilação da promessa da individualidade burguesa.

O engenho Santa Fé, a fazenda Grotão e a chácara dos Meneses evocam hospícios. Em Fogo morto, tanto o Coronel Lula, quanto Olívia, moradores da casa-grande, dão conta da vertigem do mundo senhorial. Os pobres também colhem os respingos da irracionalidade do sistema: além da loucura de Marta, tanto Zé Amaro, quanto Vitorino trazem marcas de desequilíbrios. No Grotão, a inexistência de canais de desafogo para o sujeito é atroz e todos resultam marionetes de um poder incontrolável - daí procurarem salvaguarda no culto à menina morta. 
No romance de Lúcio Cardoso os desajustes se devem ao insustentável projeto de castração a que todos foram submetidos em nome da manutenção do poderio moribundo. Entre as interdições propagadas pela obra, emerge a aniquilação do desejo e do corpo, cuja resposta serão as transgressões ou pecados, dada a forte presença da religião. Ápice das castrações e impedimentos, a figura de Timóteo é exemplar. O filho pária dos Meneses, expulso do convívio da família e das vistas do mundo externo vive, contudo, confinado aos limites da casa, em aposento secreto. Proscrito pelos seus devido à homossexualidade, impõe-se o expurgo e sobrevive em meio ao desatino. Nina, a individualidade também maldita, irá afrontar a proibição do contato. Aproximam-se em face da inobservância do lugar desejado, daí o despontar de certa camaradagem, o ensaio de certa solidariedade. No entanto, Timóteo não é apenas perseguido pela sua inadequação social, parte de seu delírio radica em uma curiosa, e talvez invertida, miragem de superioridade. Quando tomado pelo delírio, veste-se com as roupas de uma antepassada, mulher independente e ousada que também sofreu com os desmandos do grupo. De modo que a fantasia de vingança com laivos de emancipação comparte do código interno. Mesmo ao afrontar seus algozes, Timóteo fantasia a impossível independência por meio de uma figura do panteão familiar: renegada, porém endógena.

A obstrução à ordem pública condiz com o patriarcado e seus resquícios, negá-la pressupõe a interdição à subjetividade e ao desejo, à cidadania e à voz. Postura que pressupõe a sobrevivência da ordem escravista, fundada na aniquilação do outro, ancorada na superioridade de caráter senhorial. $\mathrm{O}$ anacronismo da resistência à modernidade conduzirá os sujeitos à loucura e a outros desequilíbrios psíquicos. Daí também a recorrência aos modos da morte que não se reduzem aos títulos das obras, conduzindo ao núcleo mais profundo, latente: o desvario e a morte-em-vida do sujeito como consequências de uma modernidade que se produz mediante a negação da liberdade e do outro. 


\section{Referências bibliográficas}

ARENDT, H. (2013), A condição humana, Forense universitária, Rio de Janeiro.

BACHELARD, G. (1990), A terra e os devaneios do repouso. Ensaio sobre as imagens da intimidade, Martins Fontes, São Paulo.

BOURDIEU, P. (2013), "Espaço físico, espaço social e espaço físico apropriado”, Revista Estudos Avançados, 2 (79), São Paulo, pp. 133-144, http://dx.doi.org/10.1590/S0103-40142013000300010.

BRANDÃO, L. A. (2013), Teorias do espaço literário, Perspectiva, São Paulo.

CARDOSO, L. (2009), Crônica da casa assassinada, Civilização brasileira, Rio de Janeiro.

FREYRE, G. (2000), Casa-grande \& senzala, São Paulo, Record.

FREYRE, G. (2004), Sobrados e mucambos: decadência do patriarcado rural e desenvolvimento urbano, Global Editora, São Paulo.

PENNA, C. (2001), A menina morta, Artium, Rio de Janeiro.

REGO, J. L. (1971), Fogo morto, José Olympio Rio de Janeiro.

RUFINONI, S. R. (2010), Favor e melancolia: estudo sobre A menina morta, de Cornélio Penna, Edusp/ Nankin, São Paulo. 